\title{
Microangiography and Vascular Permeability of the Subependymal Matrix in the Premature Infant
}

\author{
SACHIO TAKASHIMA AND KENZO TANAKA
}

SUMMARY: The microvascular architecture of the subependymal matrix in premature infants was studied with microangiography and benzidine stains. This revealod that the subependymal matrix is the end zone or the border zone between cerebral arteries and the collection zone of the deep cerebral veins. Focal hypoxic changes of this subependymal matrix may occur in hypoxemia and ischemia because of the characteristic architecture.

The vascular permeability of these vessels was studied in rabbits using three different molecular weights of FITCdextran. Vascular permeability was increased in the subependymal matrix by hypoxia and especially by hypoxia associated with an increased venous pressure. These findings may be related to the pathogenesis of subependymal hemorrhage in prematurity.

RÉSUMÉ: L'architecture microvasculaire de la matrice sousépendymaire des enfants prématurés fut étudiée en combinant la microangiographie et les colorations à la Benzidine. Ces études ont révélé que la matrice sousépendymaire est située au bout ou à la limite des artères cérébrales profondes. Une hypoxie focale de cette matrice sousépendymaire peut ainsi être trouvée dans l'hypoxémie et l'ischémie à cause de cette architecture particulière.

La perméabilité vasculaire de ces vaisseaux fut étudiée chez le lapin en employant du FITC-Dextran de 3 différents poids moléculaires. La perméabilité vasculaire était augmentée dans la matrice sousépendymaire par l'hypoxie et sourtout par l'hypoxie associée à une augmentation de la pression veineuse. Ces résultats ont peut-être rapport avec la pathogénèse de l'hémorragie sousépendymaire de la prématurité.

From the Departments of Pediatrics and Pathology, Kyushu University, Japan, 3-1-1 Maedashi, Fukuoka, Japan.

Reprint requests to Dr. Sachio Takashima, Department of Pediatrics, Kyushu University, 3-1-1 Maedashi, Fukuoka 812, Japan.
Hemorrhage into the subependymal matrix, the periventricular white matter or the choroid plexus is the source of intraventricular hemorrhage in premature infants. Up to 32 weeks gestational age, the most frequent sites of subependymal hemorrhage are the striae terminalis and the head of the caudate nucleus. The pathogenesis of subependymal hemorrhage has been investigated by many neonatologists and pathologists. Predisposing factors such as the large subependymal matrix (Rückensteiner et al,, 1929; Gruenwald, 1951; Saito et al., 1970) thin vessel walls (Gruenwald, 1951), hemodynamic factors concerning the internal cerebral venous system (Larroche, 1964) and fibrinolytic activity (Gilles et al., 1971; Takashima and Tanaka, 1972) have been suggested. Various causal factors such as hypoxemia (Gröntoft, 1958), trauma or compression (Schwartz, 1961; Ross et al., 1965), venous stasis (infarction; Towbin, 1968, increased venous pressure; Cole et al., 1974), venous thrombosis (Larroche, 1964), disseminated intravascular coagulation (Gray et al., 1968), hemorrhagic diathesis (Hemsath, 1934; Applayard, 1970), hypernatremia (Simmons et al., 1974; Roberton et al., 1975) and increased arterial pressure (Hambleton et al., 1976) have been defined. However, the pathogenesis of subependymal hemorrhage remains unsolved (Leech et al., 1974; Roberton, 1977).

This is a report of the microangiographic findings in normal infants and premature infants with subependymal hemorrhage. Permeability of vessels in the subependymal matrix was also studied in fetal rabbits with or without hypoxia and increased venous pressure.

\section{MATERIALS AND METHODS}

\section{l. Postmortem cerebral} microangiography

Postmortem cerebral microangiography was done on 30 neonates and 16 children without intracranial pathology and on 7 neonates with subependymal hemorrhage ruptured into the lateral ventricles. During the autopsy, a colloidal solution of barium sulfate and gelatin was hand injected into the cerebral arteries through the aortic arch for arteriography, or into cerebral veins through the superior vena cava for venography. The pressure required for some injections was measured and found to be $120-150 \mathrm{~mm} \mathrm{Hg}$. The brains were removed and suspended in $10 \%$ formalin. The fixed brains were cut coronally at $2 \mathrm{~cm}$ intervals and these sections were radiographed by soft $X$-ray technique. The sections were then cut at $1 \mathrm{~cm}$ and $0.5 \mathrm{~cm}$ intervals and radiographs made of each slice. These sections were cut again $(500$ to $1,000 \mu)$ and stained with benzidine. This stain gave a black color to the vessels containing blood and the microarchitecture of the veins and capillaries could be differentiated from the arteries which were filled with barium solution. Venograms were made when barium sulfate was injected into the superior vena cava.

2. Cerebrovascular permeability in fetal rabbits using fluorescein labelled dextrans as tracers

Pregnant rabbits weighing 3,300-4,000 $\mathrm{g}$ had Cesarean sections during which two-thirds of the uterine arteries and veins were ligated for $40 \mathrm{~min}$. before emptying the uterus. This was done at the gestational ages of 24-26 (Group I) and $28-30$ days (Group II) (full term 
$=31$ days) to produce the hypoxic fetuses. The 22 control cases were delivered before the uterine vessels were tied. Eight of 26 hypoxic fetal rabbits were dead "in utero" (6 in group I and 2 in group II) and were excluded. Arterial acid-base studies were done on 3 of the living hypoxic fetuses and the average values were $\mathrm{pH} 7.01, \mathrm{PO}_{2} 17.5$ and $\mathrm{PCO}_{2} 67.3$ $\mathrm{mmHg}$. As soon as the umbilical vessels of the live fetuses were tied, $0.4 \mathrm{ml}$ of $5 \%$ solution of FITCdextran $3(\mathrm{MW}=3,000), 20(\mathrm{MW}$ $=20,000)$ or $150(\mathrm{MW}=150,000)$ (Olsson et al., 1975; Schröder et al., 1976) was injected into the subcutaneous cervical vein for 1 to 2 $\mathrm{min}$. and the rabbit sacrificed $5 \mathrm{mi}-$ nutes later. The whole brains were fixed in $10 \%$ formalin and then cut coronally. Sections of the frontal, patietal and occipital lobes, cerebellum and brain stem were mounted in paraffin, cut at $30 \mu$, and then viewed under a fluorescence microscope.

Six rabbits of 28 days gestation with or without fetal hypoxia were injected via the cervical vein with $0.4 \mathrm{ml}$ of $5 \%$ FITC-dextran solution and then had 30 second intermittent clamping of the superior vena cava for 15 minutes together with artificial ventilatory support. The cerebral vascular permeability in those animals with intermittent clamping was compared to those without clamping.

\section{RESULTS \\ 1. Postmortem Cerebral \\ Microangiography}

Cerebral arteriography of the normal brains showed the long medullary arteries to be branching from the meningeal arteries and extending to the deep white matter and subependymal matrix. In all neonates and children the distal portions of some long medullary arteries curved at the borderline between subependymal matrix and cerebral white matter and ran parallel to the ventricular wall. They then branched into subependymal matrix and the deep white matter. In the premature neonates some of the long medullary arteries extended into the ventricular wall, and returned to spread into subependymal matrix

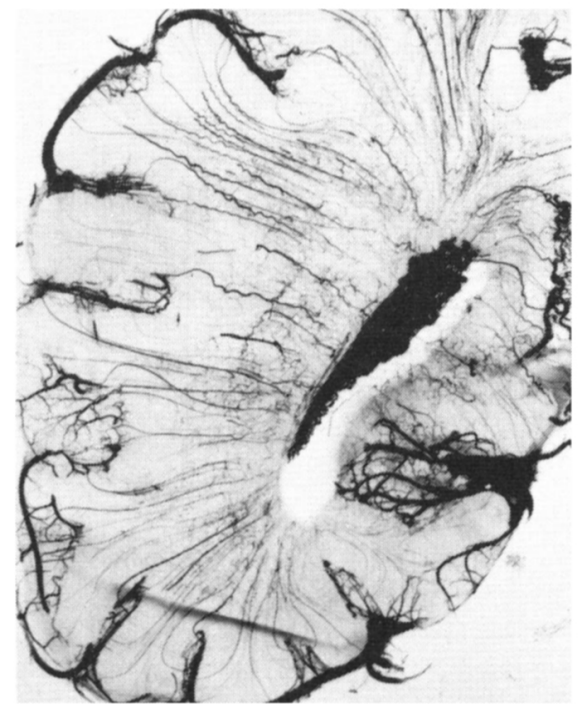

Figure 1-Arteriography of the occipital lobe in a premature infant (34 gestational weeks, hyaline membrane disease without intracranial pathology). The long medullary arteries extend to the subependymal matrix.

(Fig. 1). With maturity the subependymal matrix became narrower and the vasculature appeared flattened.

The perforating arteries of the striate and thalmic arteries branched from large arteries at the base and extended to the basal ganglia and

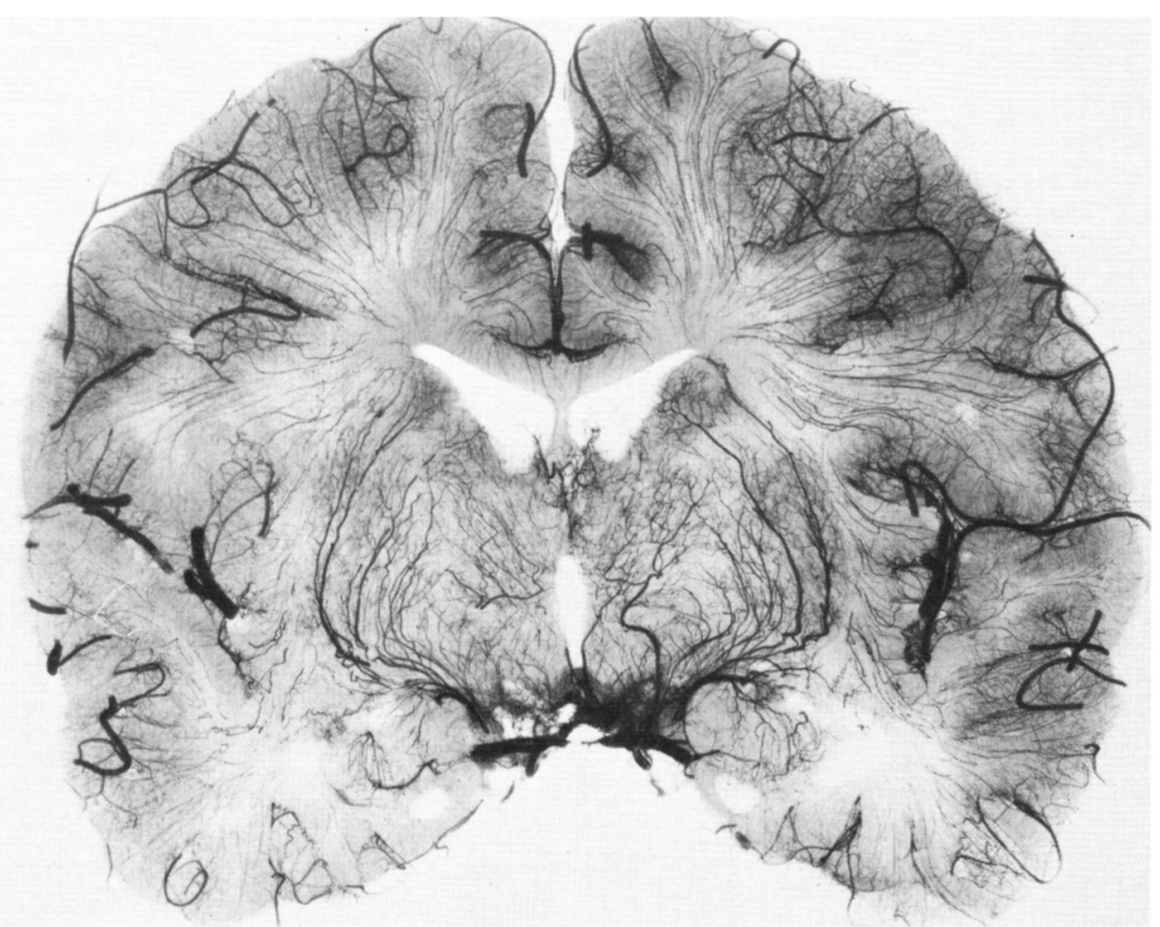

Figure 2-Arteriography of the cerebrum in a one-year-old infant (acute bronchopneumonia without intracranial pathology). The arterial border zone between the striate arteries and the thalamic arteries is apparent. 


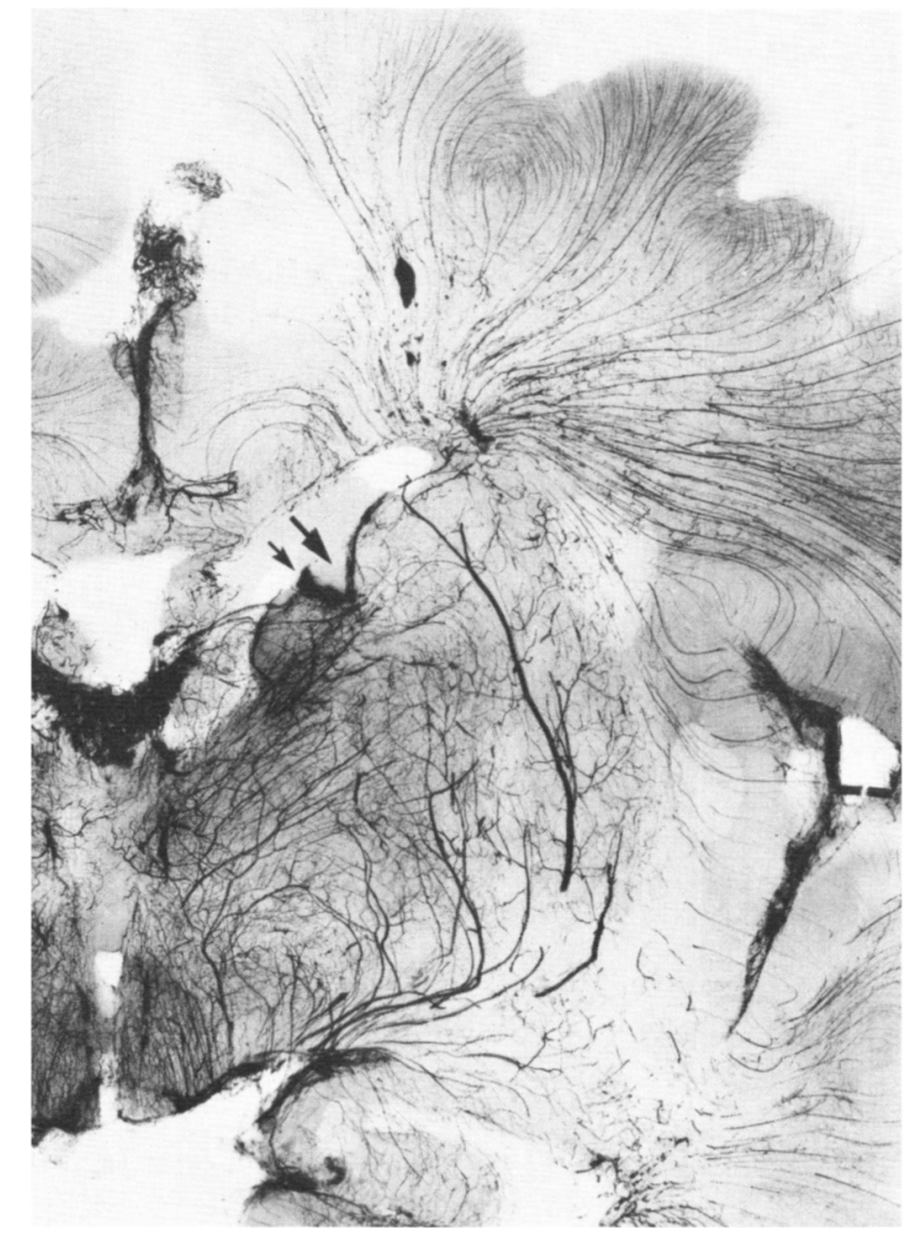

Figure 3-Arteriography of subependymal hemorrhage which has ruptured into the lateral ventricle in the premature infant (32 gestational weeks). Large arrow indicates subependymal hemorrhage, and small arrow indicates leaking lesion.

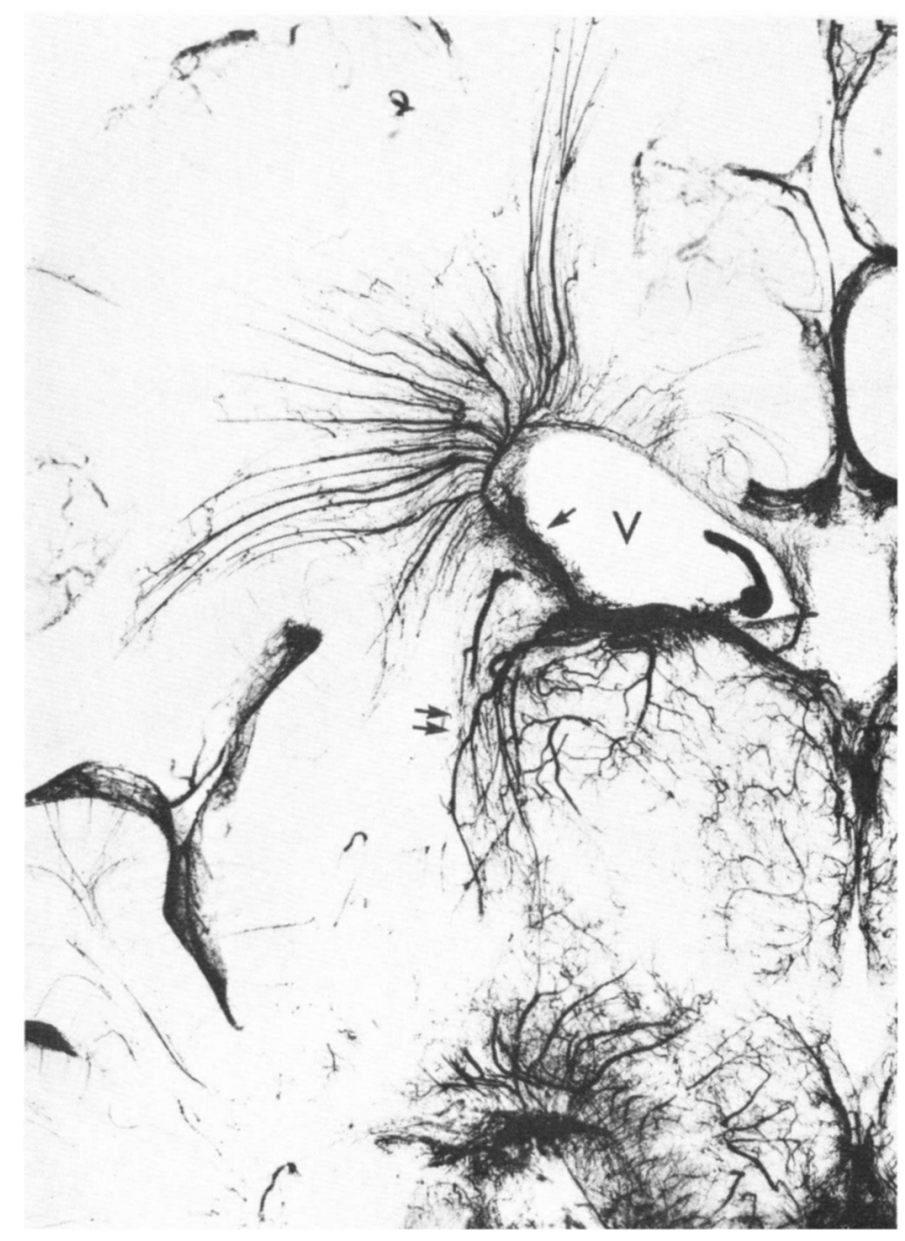

Figure 4-Venography of the deep cerebral hemisphere in the premature infant without intracranial pathology. " $\mathrm{V}$ " indicates lateral ventricle, 4 terminal vein and $\$ 4$ thalamostriate veins. the avascular area. In the deep white matter, small leaking lesions were seen in 6 of 7 neonates with subependymal hemorrhage (Fig. 3).

Cerebral venography of normal brains revealed that the deep white matter was drained by a fan-shaped leash of short and long medullary veins, which flowed vertically into subependymal veins in the subependymal matrix. Some of them ran parallel to the ventricular wall in the subependymal matrix, and then drained retrograde into the subependymal veins (Fig. 4, 5).

The subependymal veins (terminal veins) draining many small veins from the subependymal matrix, joined anteriorly with the septal, choroidal and thalamostriate veins, at the level of the Foramen of Monro to form the internal cerebral veins (Fig. 4, 5). The internal cerebral veins passed backward in the roof of the third ventricle.

In microangiography of the neonatal normal brains, stained by benzidine after barium solution was injected into the cerebral arteries, the capillary networks showed different patterns in the caudate nucleus and thalamus, cerebral white matter and subependymal matrix. The pattern of capillary network was fine and almost circular in the caudate nucleus and thalamus (Fig 6). In the cerebral white matter the network was perpendicular to the ventricular wall and larger and elliptical (Fig. 7). The capillary pattern in the subependymal matrix was elliptical and parallel to the ventricular wall

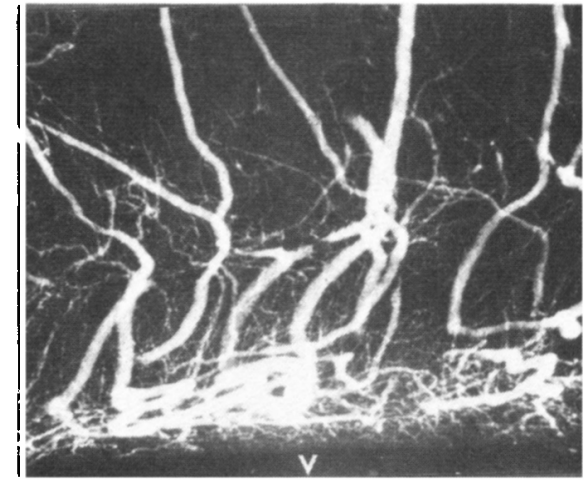

Figure 5-Microvenography of periventricular white matter of the normal premature brain. The numerous medullary veins flow into the subependymal veins in the subependymal matrix which also receive drainage from the small veins from the subependymal matrix. " $V$ " indicates lateral ventricle. 


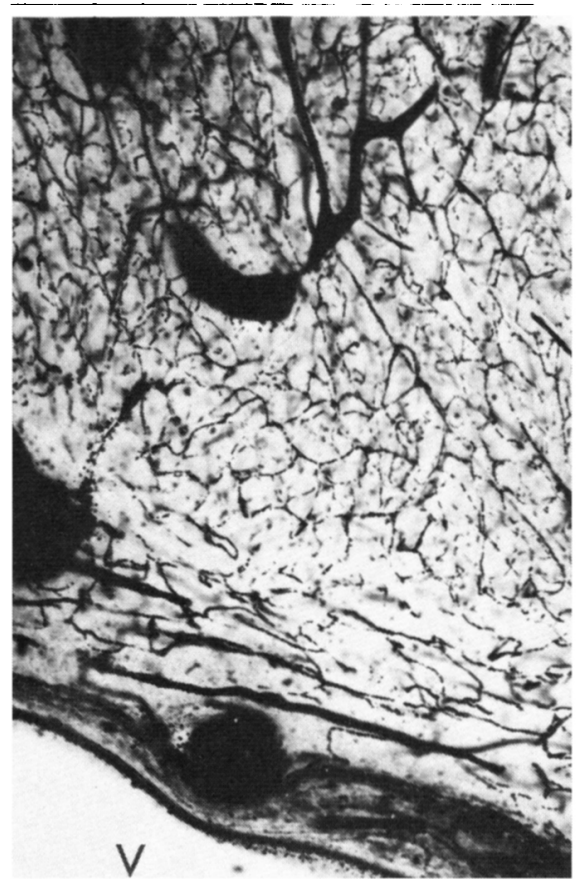

Figure 6-Microangiography of the caudate nucleus and subependymal matrix of the normal premature brain. Benzidine stains after arteriography. " $V$ " indicates lateral ventricle.

(Fig. 6, 7). The size of the latter network was intermediate, between the caudate nucleus or thalamus and the cerebral white matter.

\section{Fetal Rabbit vascular permeability with fluorescein labelled dextran tracers}

The vascular permeability in the subependymal matrix and the deep white matter varied according to the molecular weight of the tracer. FITC-dextran 3 showed the greatest permeability in both the subependymal matrix and the deep white matter. Permeability was higher in hypoxic brains than in the control brains. The deep white matter of younger brains ( 24 and 26 gestational days) showed higher permeability than that of more mature brains ( 28 and 30 gestational days) (Fig. 9, Table 2).

FITC-dextran 20 was barely recognized in the perivascular space of the subependymal matrix and cerebral white matter in some of the younger brains. The permeability in hypoxic brains was higher than in control brains (Table 3 ).

FITC-dextran 150 was not recognized at all in the perivascular spaces of the control brains, but showed slight permeability in the subependymal matrix of hypoxic brains (Fig. 9, Table 4).

In the brain of a 28 gestational day rabbit exposed to intermittent clamping of the superior vena cava, there was marked permeability of FITC-dextran 20 into the subependymal matrix (Fig. 10). The permeability in rabbits exposed to hypoxia plus increased venous pressure was higher than in rabbits with hypoxia or increased venous pressure alone.

Histological examination showed slight congestion and small hemorrhages in the subependymal matrix of the hypoxic cases (Fig. 8). There were no ventricular hemorrhages. The incidence of these hemorrhages

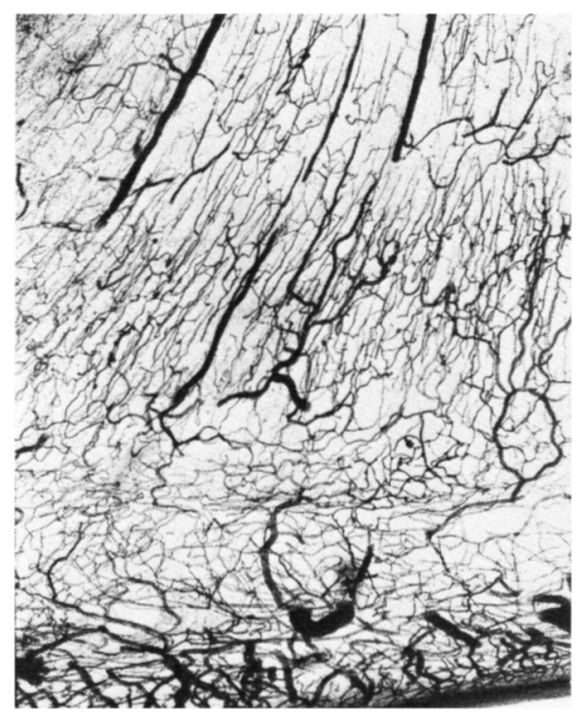

Figure 7-Microangiography of the deep white matter and subependymal matrix of the normal premature brain. Benzidine stains after arteriography.

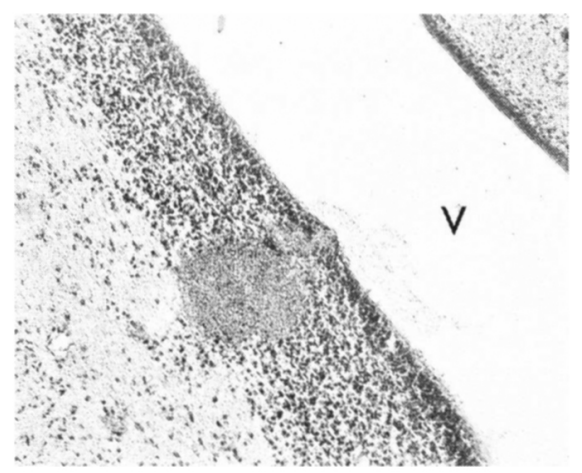

Figure 8-Subependymal hemorrhage in the hypoxic fetal rabbit following ligation of the uterine vessels. H\&E X 72 .

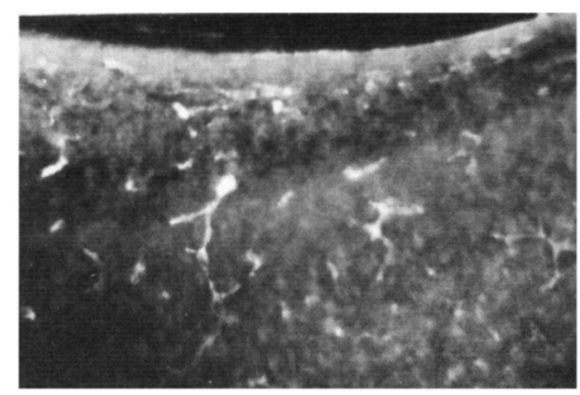

Figure 9-Subependymal matrix and white matter of an hypoxic fetal rabbit (26 gestational days) injected with FITC-dextran 150. Fluorescence micrograph.

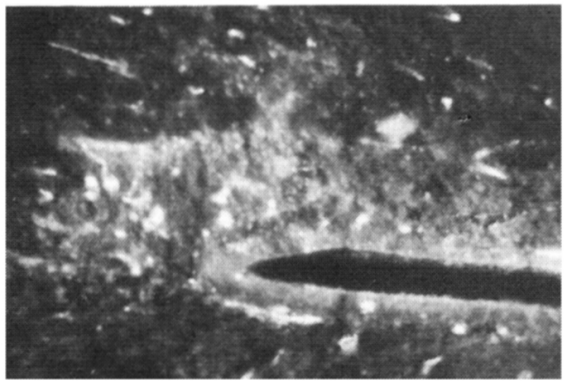

Figure 10-Subependymal matrix and white matter of a fetal rabbit ( 28 gestational days) with hypoxia and increased venous pressure. (FITCdextran 20 injected). Fluorescence micrograph.

was higher in the hypoxic fetal brains $(61.1 \%)$ than the control brains (13.6\%) (Table 1).

\section{DISCUSSION}

In the subependymal matrix, the subependymal veins joined by septal choroidal, thalamostriate and posterior terminal veins flow towards the Foramen of Monro. The direction of flow changes at an acute angle at the level of the Foramen of Monro to form the two internal cerebral veins.

Larroche (1964) felt that the risk of subependymal hemorrhage was related to hemodynamic disturbances (stasis and thrombosis) at the site of maximal flow near the Foramen of Monro and at the head of the caudate nucleus.

Hambleton et al. (1976) reported that newborn brains up to 32 weeks gestational age have a rich capillary bed in the subependymal region. The important arteries are Heubner's artery, a branch of the anterior cerebral artery, lateral 
TABLE 1

Incidence of Subependymal Hemorrhage in Hypoxic Rabbit Fetal Brains

\begin{tabular}{l|cc|cc|cc}
\multicolumn{2}{c}{} & \multicolumn{2}{c}{ TOTAL } & \multicolumn{3}{c}{ GESTATIONAL AGE (Days) } \\
\hline & & & \multicolumn{2}{|c}{$\begin{array}{c}\text { 1 } 24-\mathbf{2 6} \\
\mathbf{2 8}-\mathbf{3 0}\end{array}$} \\
\hline \multirow{3}{*}{ Hypoxic brains } & & $\%$ & & $\%$ & \multicolumn{2}{c}{$\%$} \\
Control & $\frac{11}{18}$ & 61.1 & $\frac{2}{7}$ & $28: 6$ & $\frac{9}{11}$ & 81.8 \\
& $\frac{3}{22}$ & 13.1 & $\frac{1}{10}$ & 10.0 & $\frac{2}{12}$ & 16.7 \\
\hline
\end{tabular}

Number of animals with hemorrhage

Number of animals examined

TABLE 2

Vascular Permeability of FITC-Dextran 3 in Rabbit Fetal Brain $(M W=3,000)$

Gestational Age (Days)

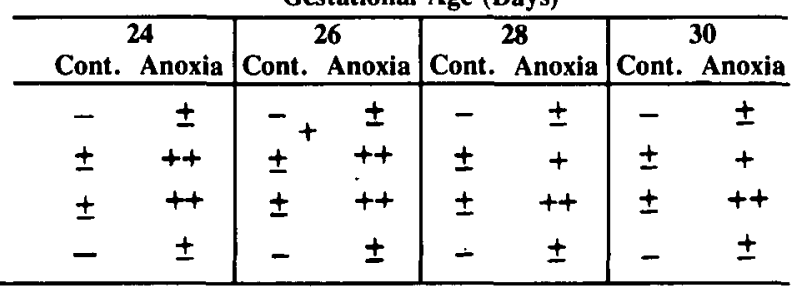

Cerebral Cortex

Cerebral White Matter

Subependymal Matrix

Basal Ganglia

- absent
\pm focal, slight
+ moderate
++ marked

TABLE 3

Vascular Permeability of FITC-Dextran 20 in Rabbit Fetal Brain $(M W=20,000)$

Gestational Age (Days)

\begin{tabular}{|c|c|c|c|}
\hline Cont. Anoxia & \begin{tabular}{|c|}
26 \\
Cont. Anoxia
\end{tabular} & $\begin{array}{c}28 \\
\text { Cont. Anoxia }\end{array}$ & $\begin{array}{c}30 \\
\text { Cont. Anoxia }\end{array}$ \\
\hline
\end{tabular}

Cerebral Cortex

Cerebral White Matter

Subependymal Matrix

Basal Ganglia

- absent

\pm focal, slight

+moderate

striate artery and anterior choroidal artery. Our work with cerebral microarteriography shows that the subependymal matrix is at the end site of the thalamostriate arteries and medullary arteries (Takashima and Tanaka, 1971). The striae terminalis - a common site of early hemorrhage and subependymal pseudocyst - is a border zone between the striate arteries and thalamic arteries, as shown in Fig. 2 and 3. Small branches of the ventriculofugal arteries in the deep white matter also spread into the subependymal matrix, although these arteries are poorly developed in premature infants (Takashima and Tanaka, 1975). Therefore, it seems reasonable to suggest that focal ischemia in the subependymal matrix, especially in the region of the striae terminalis, may be related to the border zone theory of Lindenberg (1959).

By microangiography, the subependymal matrix shows a characteristic capillary network different from the cerebral white matter and the basal ganglia and thalamus (Takashima and Tanaka, 1972). The subependymal veins run parallel to the ventricular wall, draining the medullary veins and very small veins in the subependymal matrix. Hambleton et al. (1976) found that the capillary channels often open at right angles directly into the veins in the subependymal matrix.

The subependymal matrix is prominent in premature infants and has histological characteristics of rich cellularity, poor connective tissue and thin .vascular walls (Gruenwald, 1951). Electron microscopic examination of vessels in the subependymal matrix indicates that the pericapillary spaces are surrounded by primitive germinal cells. The foot processes of astrocytes develop around the capillaries in preterm rabbits (Tanaka et al., 1977). Grunnet (1977) has demonstrated by EM deficiencies in the vascular integrity at different ages.

Gröntoft (1958) studied the blood brain barrier (BBB) of the fetus and newborn. A BBB impermeable to trypan blue is present in human fetuses 5 to $30 \mathrm{~cm}$ long. It can be easily damaged by anoxia, but its resistance to anoxia increases with the development of the fetus.

Cole et al. (1974) found the amount of lower molecular weight protein in cerebrospinal fluid increased in cases with subependymal hemorrhage, and suggested this might be due to the increased venous or capillary pressure before ventricular rupture. In our study of fetal rabbits the vascular permeability of FITC-dextran 20 was increased in the cerebral white matter, especially into the subependymal matrix of hypoxic brains. In the fetal brains with hypoxia plus increased venous pressure, the vascular permeability in the subependymal matrix was even greater.

In the pathogenesis of subependymal hemorrhage in the premature, the histological immaturity and the 
TABLE 4

Vascular Permeability of FITC-Dextran 150 in Rabbit Fetal Brain $(M W=150,000)$

Gestational Age (Days)

\begin{tabular}{lcc|cc|cc|cc} 
& \multicolumn{8}{c}{ Gestational Age (Days) } \\
\cline { 2 - 7 } & \multicolumn{2}{c|}{ Cont. Anoxia } & \multicolumn{2}{c|}{ Cont. Anoxia } & \multicolumn{2}{c|}{ Cont. Anoxia } & \multicolumn{2}{c}{$\mathbf{3 0}$} \\
Cerebral Cortex & - & - & - & - & - & - & - & - \\
Cerebral White Matter & - & \pm & - & \pm & - & - & - & \pm \\
Subependymal Matrix & - & \pm & - & \pm & - & + & \pm & \pm \\
Basal Ganglia & - & - & - & - & - & - & - & - \\
\hline
\end{tabular}

- absent

\pm focal, slight

+ moderate

vascular architecture of subependymal matrix are important predisposing factors. The subependymal matrix is a border zone or end zone and hence is subject to ischemia in any hypoxemia or hypotensive event. This leads to a localized venous stasis, increased vascular permeability and hemorrhage. Stasis and increased vascular permeability may also originate from a disturbance of the deep cerebral venous system (as shown in the rabbits) so that a retrograde mechanism may contribute to the rupture of the subependymal vessels. This study provides some evidence that the blood supply of the subependymal matrix makes it vulnerable to alterations in blood flow. Ischemia and increased venous pressure in an animal model produced increased vascular permeability. This may relate to the production of subependymal cell plate hemorrhages.

\section{ACKNOWLEDGEMENT}

We are pleased to thank Drs. Dawna Armstrong and L. Becker for their careful reading of this manuscript and numerous constructive suggestions.

\section{REFERENCES}

APPLAYARD, W. J. and COTTON, D. G. (1970). Effect of asphyxia on thrombotest values in low birthweight infants. Arch. Dis. Child. 45: 705-707.
COlE, V. A., DURBIN, G. M., OLAFFSON, A., REYNOLDS, E. O. R., RIVERS, R. P. A. and SMITH, J. F. (1974). Pathogenesis of intraventricular haemorrhage in newborn infants. Arch. Dis. Child. 49: $722-728$.

GILLES, F. H., PRICE, R. A., KEVY, S. V. and BERENBERG, W. (1971). Fibrinolytic activity in the ganglionic eminence of the premature human brain. Biol. Neonat. 18: 426-432.

GRAY, C. P., ACKERMAN, A. and FRASER, A. J. (1968). Intracranial haemorrhage and clotting defects in low birth weight infants. Lancet, I: 545-548.

GRÖNTOFT, O. (1958). Intracerebral and meningeal hemorrhages in perinatally decreased infants; intracerebral hemorrhages; pathologic-anatomical and obstetrical study. Acta Obstet. Gynec. Scand., 3:

GRUENWALD, P. (1951). Subependymal cerebral hemorrhage in premature infants, and its relation to various injuries influences at birth. Amer. J. Obstet. Gnec. 61: 1285-1292.

GRUNNET, M. L. (1977). Germinal plate hemorrhage in the premature infant. The 53rd Annual Meeting of American Association of Neuropathologists, Chicago.

HAMBLETON, G. and WIGGLESWORTH, J. S. (1976). Origin of intraventricular haemorrhage in the preterm infant. Arch. Dis. Child. 51: 651-659.

HEMSATH, F. A. (1934). Ventricular cerebral hemorrhage in the newborn infants; pathological and etiological study of 20 cases. Amer. J. Obstet. Gnec. 28: 343-354.

LARROCHE, J. C. (1964). Hemorrhagies cerebrales intraventriculaires chez le prematuré. I Anatomie et pathophysiologie. Biol. Neonat. 7: 26-56.

LEECH, R. W. and KOHNEN, P. (1974). Subependymal and intraventricular hemorrhages in the newborn. Amer. J. Path. 77: 465-475. 308-334.
LINDENBERG, R. (1959). The pathology of the arterial borderzones of the brain. J. Neuropath. Exper. Neurol. 18: 348-349.

OLSSON, Y., SVENSJO, E., ARFORS, K. E. and HULTSTROM, D. (1975). Fluorescein labelled dextrans as tracers for vascular permeability studies in the nervous system. Acta Neuropath. 33: 45-50.

ROBERTON, N. R. C. and HOWAT, P. (1975). Hypernatraemia as a cause of intracranial haemorrhage. Arch. Dis. Child. 50: $938-942$.

ROBERTON, N. R. C. and HOWAT, P. (1977). Intraventricular hemorrhage and alkali therapy (correspondence). Arch. Dis. Childh. 52: 248-249.

ROSS, J. J. and DIMMETTE, R. M. (1965). Subependymal cerebral hemorrhage in infancy. Am. J. Dis. Child. 110:531-542.

RÜCKENSTEINER, E. and ZOLLNER, F. (1929). Uber die Blutungen im Gebiete der Vena Terminalis bei Neugeborenen. Frankfurt. z. Path. 37: 568-578.

SAITO, O. and MURATA, B. (1970), Neonatal intracranial hemorrhage; intraventricular hemorrhage. Pediatrics (Japanese) 11; 734.

SCHRÖDER, U., ARFORS, K. E. and TANGEN, O. (1976). Stability of fluorescein labelled dextrans in vivo and in vitro. Microvascular Research, 11: 33-39.

SCHWARTZ, P. (1961). Birth injuries of the newborn: morphology, pathogenesis, clinical pathology and prevention. Hafner, New York.

SIMMONS, M. A., ADCOCK, E. W., BARD, H. and BATTAGLIA, F. C. (1974). Hypernatremia and intracranial hemorrhage in neonates. New Engl. J. Med. 291: 6-10.

TAKASHIMA, S. and TANAKA, K. (1971). Postmortem angiography of the neonatal cerebral vascular system. 2. Vascular architecture of cerebral cortex and white matter in the neonates. Acta Neonat. Japonica 7: 222-228 (Japanese).

TAKASHIMA, S. and TANAKA, K. (1972) Microangiography and fibrinolytic activity in subependymal matrix of the premature brain. Brain and Development 4: 222-227 (Japanese).

TAKASHIMA, S. and TANAKA, K. (1975). Development of ventriculofugal arteries and periventricular leukomalacia in the deep white matter. Acta Neonat. Jap. 11: 392-394 (Japanese).

TANAKA, K., TAKASHIMA, S. and SUEISHI, K. (1977). Pathology of neonatal cerebral circulatory disturbances. Pediatric clinics, 30: 715-724 (Japanese).

TOWBIN, A. (1968). Cerebral intraventricular hemorrhage and subependymal matrix infarction in the fetus and premature newborn. Amer. J. Pathol. 52: 121-139. 